Quim. Nova, Vol. 36, No. 2, 348-353, 2013

\title{
PATENTEAMENTO EM NANOTECNOLOGIA NO BRASIL: DESENVOLVIMENTO, POTENCIALIDADES E REFLEXÕES PARA O MEIO AMBIENTE E A SAÚDE HUMANA
}

\author{
Leonardo da Silva Sant'Anna \\ Faculdade de Direito, Universidade Estadual do Rio de Janeiro, Rua São Francisco Xavier, 524 20550-900 Rio de Janeiro - RJ, Brasil \\ Maria Simone de Menezes Alencar \\ Instituto de Comunicação e Informação Científica e Tecnológica em Saúde /Fiocruz, Av. Brasil, 4305, 21045-360 Rio de Janeiro \\ - RJ, Brasil \\ Aldo Pacheco Ferreira* \\ Centro de Estudos da Saúde do Trabalhador e Ecologia Humana, Escola Nacional de Saúde Pública Sérgio Arouca/Fiocruz, R. \\ Leopoldo Bulhões, 1480, 21041-210 Rio de Janeiro - RJ, Brasil
}

Recebido em 22/5/12; aceito em 29/8/12; publicado na web em 1/2/2013

\begin{abstract}
NANOTECHNOLOGY PATENTING IN BRAZIL: DEVELOPMENT, POTENTIALITIES AND REFLECTIONS FOR THE ENVIRONMENT AND HUMAN HEALTH. Nanotechnology developments continue to be produced at exponential rates for a wide and diverse range of applications. In this paper was done a study of technological forecasting in nanotechnology applied to health, based on information drawn in Brazil from 1991 to 2010. The longitudinal evolutions of the number of patent applications, their topics, and their respective patent families have been evaluated for the total global activity. There were obtained 1352 patent applications in this period. It were analyzed the legal nature of the depositors, the year of deposit, depositors' home countries and processes. It has been a goal subsidizes the policy-makers to adapt and modernize the regulatory framework on nanotechnology and risks involving health as a strategic area in the politics of Science.
\end{abstract}

Keywords: patenting; nanotechnology; number of patent applications.

\section{INTRODUÇÃO}

O desenvolvimento da nanotecnologia tem sido apontado como uma nova revolução tecnológica, devido ao seu enorme potencial de inovação para o desenvolvimento industrial e econômico. ${ }^{1-3}$ Dessa forma, a nanotecnologia é definida como um campo científico multidisciplinar baseado no desenvolvimento, na caracterização, na produção e na aplicação de estruturas, dispositivos e sistemas com forma e tamanho na escala nanométrica, que podem apresentar propriedades químicas, físico-químicas e comportamentais diferentes daquelas apresentadas em escalas maiores. ${ }^{2,4}$

No Brasil, estudos relacionados à nanotecnologia vêm sendo incentivados pelo Conselho Nacional de Desenvolvimento Científico e Tecnológico (CNPq) e Ministério de Ciência e Tecnologia (MCT), desde 2001, quando foram criadas 4 redes de pesquisa em Nanociência e Nanotecnologia, nas seguintes áreas: Materiais nanoestruturados, Interfaces e Nanotecnologia molecular, Nanobiotecnologia e Nanodispositivos semicondutores. ${ }^{5}$ Segundo o relatório "Nanotecnologia: Investimentos, Resultados e Demandas", divulgado em 2006 pelo MCT, esta iniciativa permitiu que entre 2002 e 2005 houvesse o envolvimento de 77 instituições de ensino e pesquisa, 13 empresas, além de 300 pesquisadores que publicaram mais de 1000 artigos científicos e depositaram mais de 90 patentes. ${ }^{5,6}$

O Brasil vem investindo cada vez mais em nanotecnologia. A produção científica em Nanociência e Nanotecnologia (N\&N) no Brasil desfruta de certo prestígio no cenário mundial, com uma comunidade científica composta por cerca de 3 mil indivíduos e a melhor infraestrutura da América Latina. ${ }^{3}$ Entretanto, quando se trata de produção de inovações percebe-se que o país precisa melhorar, apesar do Governo Federal estar investindo em uma série de instrumentos

*e-mail: aldopachecoferreira@gmail.com que visam fortalecer o potencial inovador brasileiro em N\&N, como os editais do CNPq e da Financiadora de Estudos e Projetos (FINEP) voltados ao desenvolvimento tecnológico de produtos, processos ou serviços nesta área, bem como em estratégias regulamentadoras como a Lei de Inovação, Lei n ${ }^{\circ} 10.973$ de 2004, ${ }^{7}$ que "estabelece medidas de incentivo à inovação e à pesquisa científica e tecnológica no ambiente produtivo, com vistas à capacitação, ao alcance da autonomia tecnológica e ao desenvolvimento industrial do País".

Esta nova tecnologia representa potencialmente um enorme mercado mundial, sendo que os países que mais investem em nanotecnologia são os Estados Unidos da América, Europa e Japão, entretanto países como a Rússia, China, Índia e Brasil têm feito investimentos significativos no setor nos últimos anos. ${ }^{2,8}$ Estima-se que os investimentos superam 2 bilhões de dólares por ano. ${ }^{9}$ Porém, em relação ao depósito de patentes em nanotecnologia, apesar do Brasil ter demonstrado um grande potencial para desenvolvimento na área, o número de patentes registradas no Instituto Nacional de Propriedade Industrial (INPI) em relação a outros países ainda não é expressivo. ${ }^{10}$

Dessa forma, o Brasil caracteriza-se como um país em estágio intermediário de desenvolvimento tecnológico, mesmo com a ampliação significativa do investimento em atividades de Ciência e Tecnologia (C\&T) nos últimos anos. O dispêndio em $\mathrm{C} \& \mathrm{~T}$ em relação ao produto interno bruto (PIB) passou de 1,30\%, em 2000, para 1,57\% em 2009. ${ }^{11}$ Nesse sentido, um dos principais propósitos do plano plurianual (PPA) 2012-2015 nas Políticas de Desenvolvimento Produtivo e Ambiental é ampliar os investimentos empresariais em P\&D de 0,59\% do PIB, em 2010, para 0,9\% do PIB, em 2015. ${ }^{12}$ Pretende-se, ainda, aumentar de 22,3 para $30 \%$ a participação de empresas inovadoras que utilizam ao menos um dos diferentes instrumentos de apoio governamental à inovação e elevar de 3.425 para 5.000 o número de sociedades empresariais que fazem Pesquisa e Desenvolvimento (P\&D) contínuo. ${ }^{13}$ 
Dentre outras, são consideradas prioritárias para a ampliação dos investimentos em P\&D as relacionadas ao complexo econômico-industrial da saúde, incluindo tecnologias transversais da biotecnologia e nanotecnologia. ${ }^{13-16}$ Nessa direção, os potenciais riscos à saúde e ao ambiente tornam-se o assunto de grande relevância. ${ }^{17-19}$

Destacam-se a referência genérica a transformações do modo de vida que ocorreriam como consequência do desenvolvimento da nanotecnologia, tais como, dilemas éticos, possível incremento da desigualdade social, além dos riscos ocupacionais para trabalhadores de laboratórios e da indústria e na saúde pública. ${ }^{17-20} \mathrm{Em}$ síntese, a preocupação com as implicações econômicas, sociais e éticas das nanotecnologias e seus potenciais riscos é bastante tênue nas perspectivas sobre nanotecnologia. Isso tem seu correlato nas políticas públicas, que só de forma incipiente têm considerado essas questões. ${ }^{18}$ Essa é uma deficiência expressiva, dada a existência no país de algumas situações controversas que atingiram a cena pública nos últimos anos: a pesquisa com células tronco e os alimentos geneticamente modificados.

Pelo uso da bibliometria neste artigo para análise de patentes, tomou-se como base um amplo estudo desenvolvido por pesquisadores de PREST (Manchester University) onde analisaram cerca de 800 estudos de prospecção em todo o mundo. ${ }^{21} \mathrm{~A}$ bibliometria aplicada a patentes (patentometria), ${ }^{20,22}$ por sua vez, oferece inteligência estratégica sobre tecnologias e pode revelar vantagens competitivas baseadas na liderança em desenvolvimento tecnológico. O uso de indicadores bibliométricos pode ser um método eficiente para comparar, monitorar e analisar atividades de pesquisa em uma área temática ou novo campo. ${ }^{22}$

Como qualquer método, o uso de patentes como indicador de inovação tem limitações: inovações nem sempre correspondem a invenções patenteadas, e nem todas as invenções patenteadas possuem valor econômico ou tecnológico. ${ }^{23,24} \mathrm{Ou}$ seja, nem todos os produtos são patenteados e nem todas as patentes geram produtos. Considerando, no entanto, uma área de intensa mobilidade de capital como a nanotecnologia, a dinâmica de patenteamento oferece uma inteligência potencialmente valiosa sobre produtos emergentes. ${ }^{2.5}$ $\mathrm{O}$ uso de patentes em nanotecnologia é, portanto, um instrumento válido para a análise de riscos potenciais à saúde pública e ambiental no Brasil. ${ }^{26-28}$

Os estudos prospectivos utilizam-se de diversas metodologias para oferecer subsídios de apoio aos processos de planejamento estratégico de organizações e sociedades empresariais, bem como para apoiar as políticas públicas e setoriais. ${ }^{29} \mathrm{~A}$ metodologia prospectiva também tem sido utilizada para definição de prioridades de investimento e de agenda em áreas tais como educação, saúde e ações sociais. ${ }^{30}$ Com base em informações extraídas de documentos de patentes do INPI, tem-se como meta subsidiar os formuladores de políticas públicas sobre riscos envolvendo nanotecnologia e saúde, por ser uma área estratégica na política de Ciência, Tecnologia e Inovação do país.

\section{PARTE EXPERIMENTAL}

Este estudo adota a consulta léxica, a mais popular, também utilizada por diversos outros autores em estudos bibliométricos relativos à nanotecnologia. ${ }^{30-32} \mathrm{~A}$ estratégia adotada nesta pesquisa utiliza um mix de diversos estudos, que ressaltam que a estratégia de busca necessita de atualização constante, visto que a nanotecnologia ainda está em estágio emergente e que o uso de documentos de patentes possui relevância para o tema. ${ }^{33}$

Utilizou-se uma abordagem quantitativa, a partir de uma análise bibliométrica de dados obtidos na base de patentes do INPI. Os dados foram coletados em dezembro de 2011, data da publicação da última
RPI de 2011, utilizando 18 termos relacionados à nanotecnologia. A escolha dos termos de busca foi baseada na metodologia adotada pelo INPI na publicação sobre nanotecnologia da Série Alerta Tecnológico, ${ }^{13}$ editada para divulgar os títulos dos pedidos de patentes publicados mundialmente a cada 6 meses. Além dos termos propostos pelo INPI, outros foram incluídos, baseados em artigos que tratam de estratégias de busca ou bibliometria em nanotecnologia. ${ }^{928-31}$ Os termos foram truncados de forma a otimizar e maximizar os resultados e foram os seguintes: Dendrimer*, Nanod*, Nanom*, Fio* Quantic*, Nanoe*, Nanonet*, Fuleren*, Nanof*, Nanop*, Grafen*, Nanog*, Nanos*, Nanoh*, Nanob*, Nanot*, Nanoc*, Nanoi* e Ponto* Quantic*.

Para efetuar este levantamento foram selecionados os documentos de patentes (patentes de invenção, modelos de utilidades e certificados de adição) que continham em seu título e/ou resumo, pelo menos, um dos 18 termos citados anteriormente. Os modelos de utilidade foram incluídos por também serem suscetíveis de aplicação industrial e os certificados de adição, que são complementos de invenções já realizadas, também foram incluídos no estudo.

Quanto aos dados referentes ao processo jurídico, os seguintes campos foram coletados: data de depósito; título do pedido - título dado pelo inventor à sua invenção; nome do depositante - pessoa física ou jurídica titular do pedido de patente ou patente; notificação - fase do processo patentário; número da Revista de Propriedade Intelectual (RPI) que publicou a notificação; data de publicação da RPI; país de origem do depositante e, classe internacional de patentes (CIP) - principal do pedido de patente.

Visando focar as patentes na área de saúde foram selecionadas apenas aquelas com a CIP principal relacionada a subsetores da saúde, adaptando metodologia proposta por Antunes et al. ${ }^{30}$ Nesta metodologia, o setor de saúde é segmentado em quatro subsetores, baseado nas seções de saúde existentes da CIP, conforme ilustrado na Tabela 1.

Os quatro subsetores são: cuidados odontológicos, drogas, kits de diagnósticos, equipamentos e aparatos para tratamento e cuidados médicos, o último está dividido em sete subclasses. Estes quatro subsetores são tratados na seção A (necessidades humanas), subseção "saúde; salvamento; recreação" classe A61 (ciência médica ou veterinária; higiene). Para o subsetor de kits de diagnósticos e outras subclasses (G01 e C12Q) também foram utilizados para complementar a subclasse A61B.

O ponto de corte das análises foi feita com base no Princípio de Pareto. ${ }^{34}$ Os depositantes foram categorizados em pessoas físicas e jurídicas, sendo nestas últimas destacadas aquelas caracterizadas como Instituições de Ciência e Tecnologia (ICT), a saber: universidades, fundações universitárias e de fomento e institutos de tecnologia, que apesar de serem pessoas jurídicas foram destacadas face às suas peculiaridades.

\section{Tratamento de dados}

Como havia patentes que se repetiam por conterem mais de um termo, foi necessário um tratamento de depuração de duplicatas, objetivando um conjunto de patentes únicas antes de se proceder à análise. Além disso, não há na base de dados do INPI padronização no nome dos depositantes, o que dificulta a quantificação deste campo. Para facilitar estas etapas, bem como para gerar relatórios para análise dos resultados de forma mais consistente foi utilizada uma ferramenta automatizada de mineração de dados, o software Vantagepoint 7.1, SearchTechnology®.

\section{RESULTADOS E DISCUSSÃO}

Após a primeira etapa da busca que foi realizada com a presença de pelo menos um dos termos em um dos campos selecionados, foi 
Tabela 1. Subsetores da saúde e respectivas subclasses da classe internacional de patentes (1991-2010)

\begin{tabular}{|c|c|c|}
\hline Subsetores & Subclasses da CIP & Descrição \\
\hline Dental & $\mathrm{A} 61 \mathrm{C}$ & Odontologia; aparelhos ou métodos para higiene oral ou higiene dental \\
\hline \multirow{2}{*}{ Drogas } & A61K & Preparações para finalidades médicas, odontológicas ou higiênicas \\
\hline & A61P & Atividade terapêutica específica de compostos químicos ou preparações medicinais \\
\hline \multirow{3}{*}{ Kits diagnósticos } & G01N & Investigação ou análise dos materiais pela determinação de suas propriedades químicas ou físicas \\
\hline & C12Q & $\begin{array}{l}\text { Processos de medição ou ensaio envolvendo enzimas ou micro-organismos; suas composições ou seus papéis } \\
\text { de teste; processos de preparação dessas composições; controle responsivo a condições do meio nos processos } \\
\text { microbiológicos ou enzimáticos }\end{array}$ \\
\hline & A61B & Diagnóstico; cirurgia; identificação \\
\hline \multirow{7}{*}{$\begin{array}{l}\text { Equipamentos e } \\
\text { aparatos para } \\
\text { tratamento e } \\
\text { cuidados médicos }\end{array}$} & $\mathrm{A} 61 \mathrm{~F}$ & $\begin{array}{l}\text { Filtros implantáveis nos vasos sanguíneos; próteses; dispositivos que promovem desobstrução ou previnem } \\
\text { colapso de estruturas tubulares do corpo; dispositivos ortopédicos, de enfermagem ou anticoncepcionais; fo- } \\
\text { mentação; tratamento ou proteção dos olhos ou ouvidos; ataduras, curativos ou almofadas absorventes; estojos } \\
\text { para primeiros socorros }\end{array}$ \\
\hline & A61G & $\begin{array}{l}\text { Transporte, pessoal, ou acomodação especialmente adaptada para pacientes ou pessoas deficientes físicas; mesas } \\
\text { ou cadeiras cirúrgicas; cadeiras de dentista; dispositivos para sepultamento }\end{array}$ \\
\hline & $\mathrm{A} 61 \mathrm{H}$ & $\begin{array}{l}\text { Aparelhos de fisioterapia; dispositivos para localizar ou estimular os pontos de reflexibilidade do corpo; respiração } \\
\text { artificial; massagem; dispositivos de banho para usos especiais terapêuticos ou de higiene ou partes específicas } \\
\text { do corpo }\end{array}$ \\
\hline & A61J & $\begin{array}{l}\text { Recipientes especialmente adaptados para finalidades médicas ou farmacêuticas; dispositivos ou métodos espe- } \\
\text { cialmente adaptados para converter os produtos farmacêuticos em formas físicas especiais ou de administração; } \\
\text { dispositivos para administrar alimentos ou remédios por via oral; chupetas de criança; escarradeiras }\end{array}$ \\
\hline & A61L & $\begin{array}{l}\text { Métodos ou aparelhos para esterilizar materiais ou objetos em geral; desinfecção, esterilização ou desodorização } \\
\text { do ar; aspectos químicos de ataduras, curativos, almofadas absorventes ou artigos cirúrgicos; materiais para } \\
\text { ataduras, curativos, almofadas absorventes ou artigos cirúrgicos }\end{array}$ \\
\hline & $\mathrm{A} 61 \mathrm{M}$ & $\begin{array}{l}\text { Dispositivos para introduzir matérias no corpo ou depositá-las sobre o mesmo; dispositivos para fazer circular } \\
\text { matérias no corpo ou para dele as retirar; dispositivos para produzir ou por fim ao sono ou à letargia }\end{array}$ \\
\hline & A61N & Eletroterapia; magnetoterapia; terapia por radiação; terapia por ultrassom \\
\hline
\end{tabular}

encontrada duplicidade de resultado. Tal fato se deu porque a interface de busca no INPI tem limitação quanto ao número de termos a ser incluído em cada busca, gerando, portanto, duplicidade nos resultados. A etapa de refinamento para retirada de duplicatas gerou uma base de dados de 1352 pedidos de patentes, fonte das análises que se seguem. Com base na Figura 1 observa-se que o primeiro pedido em nanotecnologia descrito e apresentado na base de dados do INPI ocorreu em 08/11/1991 e o último em 29/11/2011, dentro do período estudado. Ressalta-se, também, que o pico no número de pedidos de patentes ocorreu em 2006, provavelmente fruto dos diversos editais de financiamento da FINEP e do CNPq voltados para a nanotecnologia, que começaram a partir de 2003, e que são detalhados na publicação da Agência Brasileira de Desenvolvimento Industrial (ABDI). ${ }^{35}$

Cabe destacar que o incremento observado em 1997, que ocorre em todas as áreas, se deve à entrada em vigor da Lei de Propriedade

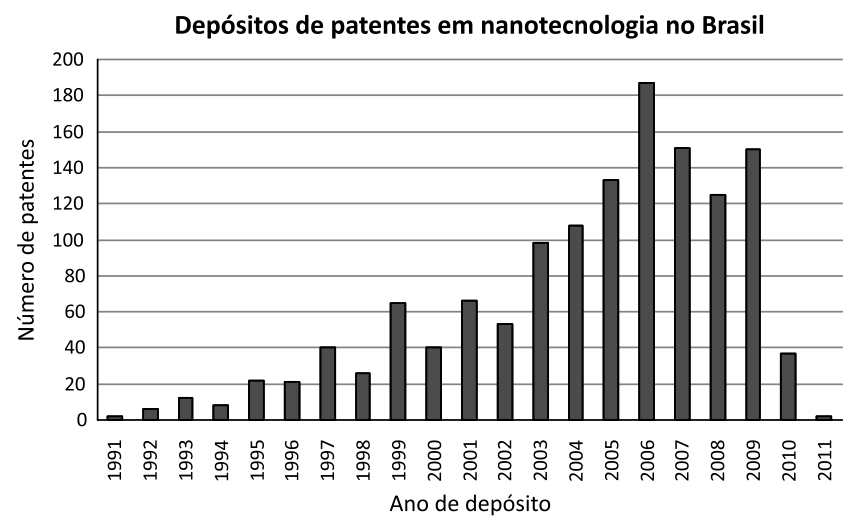

Figura 1. Evolução histórica dos depósitos de patentes no Brasil (1991-2010)
Industrial (LPI), Lei no 9279/1996. ${ }^{36}$ Esta LPI revogou a Lei no 5772 de 1971, o CPI e atualizou a legislação brasileira, que era protecionista ao extremo, com a finalidade de adequá-la à competição mundial existente. $\mathrm{O}$ acordo Propriedade Intelectual relacionada ao Comércio (TRIPS) incorporado ao nosso ordenamento através do Decreto $\mathrm{n}^{\circ} 1355$, de 1994, foi sem dúvida fator fundamental para atualização legislativa.

A Lei ${ }^{\circ} 10196$ de $2001^{37}$ trouxe importantes alterações ao texto da LPI, entre as quais permitiu que pedidos de patentes depositados até 31 de dezembro de 1994 referentes a produtos químico-farmacêuticos e medicamentos, e seus processos de obtenção ou modificação, fossem indeferidos, bem como o indeferimento dos pedidos de patentes de processos de obtenção de produtos químico-farmacêuticos e medicamentos apresentados entre $1^{\circ}$ de janeiro de 1995 e 14 de maio de 1997. Além de ressaltar que a concessão de patentes para produtos e processos farmacêuticos dependerá da anuência prévia da Agência Nacional de Vigilância Sanitária (ANVISA), Art.v 229-C.

De acordo com o parecer $n^{\circ}$ 337/PGF/FA/2010, de 07/01/2011, cabe ao INPI analisar o cumprimento dos requisitos para a concessão de uma patente prevista na legislação que trata do assunto. Já a ANVISA não pode recusar a concessão da anuência prevista no art. 229-C da LPI, lastreada em requisitos de patenteabilidade, sendo que nada obsta que a ANVISA apresente ao INPI considerações sobre o disposto no artigo 31, para avaliar a segurança e eficácia do medicamento.

Visando focar no patenteamento em nanotecnologia ligado ao setor de saúde, foi feito um corte das patentes ligadas a este segmento através da CIP, conforme metodologia exposta anteriormente, resultando em 373 pedidos de patentes, que representam $27,58 \%$ dos depósitos no período estudado. Observa-se na Tabela 2 que o subsetor de fármacos é o maior foco de patenteamento em nanotecnologia no Brasil, correspondendo a 79\% dos depósitos no período do estudo. 
Tabela 2. Distribuição das patentes de nanotecnologia depositadas no Brasil por subsetores da saúde (1991-2010)

\begin{tabular}{|c|c|c|}
\hline Subsetor/ patentes & $\begin{array}{c}\mathrm{N}^{\circ} \text { de pedidos de } \\
\text { patentes }\end{array}$ & Grupo principal \\
\hline \multirow{2}{*}{ Drogas (289) } & 287 & a61k - preparações para finalidades médicas, odontológicas ou higiênicas \\
\hline & 2 & a61p - atividade terapêutica específica de compostos químicos ou preparações medicinais \\
\hline dental (2) & 2 & a61c - odontologia;aparelhos ou métodos para higiene oral ou higiene dental \\
\hline \multirow{3}{*}{ kits diagnósticos (38) } & 29 & g01n - investigação ou análise dos materiais pela determinação de suas propriedades químicas ou físicas \\
\hline & 7 & $\begin{array}{l}\text { c12q - processos de medição ou ensaio envolvendo enzimas ou micro-organismos; suas composições ou seus } \\
\text { papéis de teste; processos de preparação dessas composições; controle responsivo a condições do meio nos } \\
\text { processos microbiológicos ou enzimáticos }\end{array}$ \\
\hline & 2 & a61b - diagnóstico; cirurgia; identificação \\
\hline \multirow{3}{*}{$\begin{array}{l}\text { equipamentos e } \\
\text { aparatos para } \\
\text { tratamento e } \\
\text { cuidados } \\
\text { médicos (39) }\end{array}$} & 10 & $\begin{array}{l}\text { a61f - filtros implantáveis nos vasos sanguíneos; próteses; dispositivos que promovem desobstrução ou previ- } \\
\text { nem colapso de estruturas tubulares do corpo; dispositivos ortopédicos, de enfermagem ou anticoncepcionais; } \\
\text { fomentação; tratamento ou proteção dos olhos ou ouvidos; ataduras, curativos ou almofadas absorventes; estojos } \\
\text { para primeiros socorros }\end{array}$ \\
\hline & 24 & $\begin{array}{l}\text { a611 - métodos ou aparelhos para esterilizar materiais ou objetos em geral; desinfecção, esterilização ou desodo- } \\
\text { rização do ar; aspectos químicos de ataduras, curativos, almofadas absorventes ou artigos cirúrgicos; materiais } \\
\text { para ataduras, curativos, almofadas absorventes ou artigos cirúrgicos }\end{array}$ \\
\hline & 5 & a61n - eletroterapia; magnetoterapia; terapia por radiação; terapia por ultrassom \\
\hline
\end{tabular}

Foi avaliada a natureza jurídica dos depositantes, considerando se o mesmo é pessoa jurídica ou pessoa física, destacando as instituições de C\&T e as parcerias existentes. Observa-se que no conjunto total das patentes depositadas em nanotecnologia e saúde no Brasil, $66,7 \%$ são de pessoas jurídicas, $18,5 \%$ de Instituições de C\&T, $10 \%$ de pessoas físicas e o restante são parcerias entre essas tipologias.

No entanto, ao se observar separadamente a natureza jurídica dos extratos de residentes e não residentes há uma diferença considerável. Dentre os não residentes, os depositantes concentram-se nas pessoas jurídicas, com 151 (82,5\%) depósitos no período. Já dentre os residentes, as Instituições de $\mathrm{C} \& \mathrm{~T}$ têm o maior número de depósitos, representando 43,3\% (20 depósitos únicos e 9 em parcerias entre ICTs). Interessante observar que em segundo lugar vêm os depósitos de pessoas físicas, seja individualmente (11) ou parcerias de pessoas físicas (6), totalizando 25,4\% dos depósitos no período. Por fim, as pessoas jurídicas representam $22,4 \%$ dos pedidos, incluídas aí 6 patentes de parcerias entre sociedades empresariais (Figura 2).

\section{Tipologia dos depositantes}

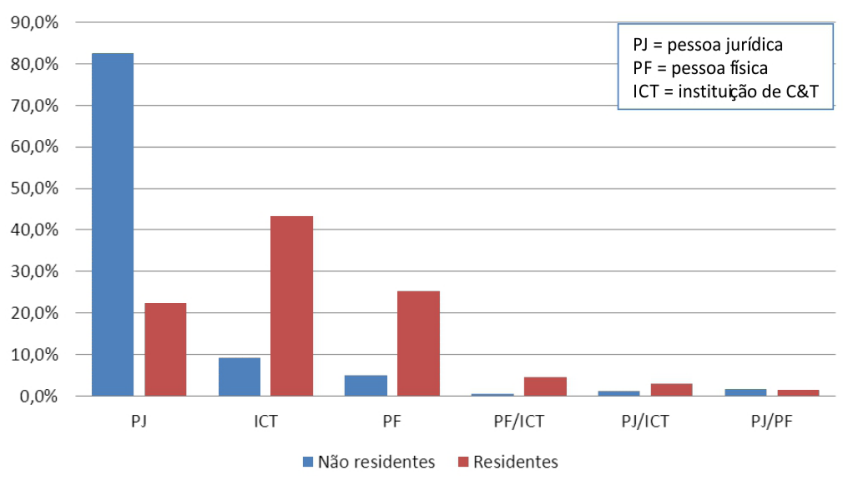

Figura 2. Tipologia por origem dos depositantes de patentes em nanotecnologia no Brasil (1991-2010)

Depositantes de 22 diferentes países realizaram depósito de patentes de nanotecnologia em saúde no período do estudo, conforme pode ser observado na Tabela 3. Embora o Brasil esteja em primeiro lugar, percentualmente representa apenas $27 \%$ dos depósitos no período.
Tabela 3. País de origem dos depositantes de patentes em nanotecnologia no Brasil (1991-2010)

\begin{tabular}{cc}
\hline País de origem do depositante & $\mathrm{N}^{\mathrm{o}}$ de patentes \\
\hline Brasil & 101 \\
Estados Unidos & 101 \\
Alemanha & 36 \\
França & 34 \\
Irlanda & 28 \\
Suíça & 13 \\
Espanha & 10 \\
Holanda & 7 \\
Austrália & 6 \\
Canadá & 6 \\
Índia & 5 \\
Reino Unido & 5 \\
Itália & 4 \\
Suécia & 4 \\
Coréia do Sul & 3 \\
Japão & 3 \\
Israel & 1 \\
China & 1 \\
Cuba & 1 \\
Finlândia & 2 \\
Portugal & 1 \\
Rússia & \\
& 3 \\
\hline & 1 \\
\hline & \\
\hline
\end{tabular}

Voltando ao país de origem dos depositantes, um olhar mais atento aos 5 países de maior expressão em termos de número de depósitos no período revela que o Brasil apresenta uma tendência de crescimento significativa. A Figura 3 mostra a evolução do número de patentes por quinquênio, indicando que 2 países apresentam taxa de crescimento expressivo: Brasil e Irlanda. No Brasil o número de 
depósitos aumenta de 15 no quinquênio 2001-2005 para 52 patentes no período seguinte, representando crescimento de $246 \%$. A Irlanda passa de 4 para 18 depósitos neste mesmo intervalo de tempo, o que significa $350 \%$, em que pese o pequeno valor em números absolutos. No caso do Brasil, várias instituições são depositantes, como será discutido posteriormente, mas os depósitos da Irlanda se concentram na Elan Pharma International Ltd, indústria farmacêutica.

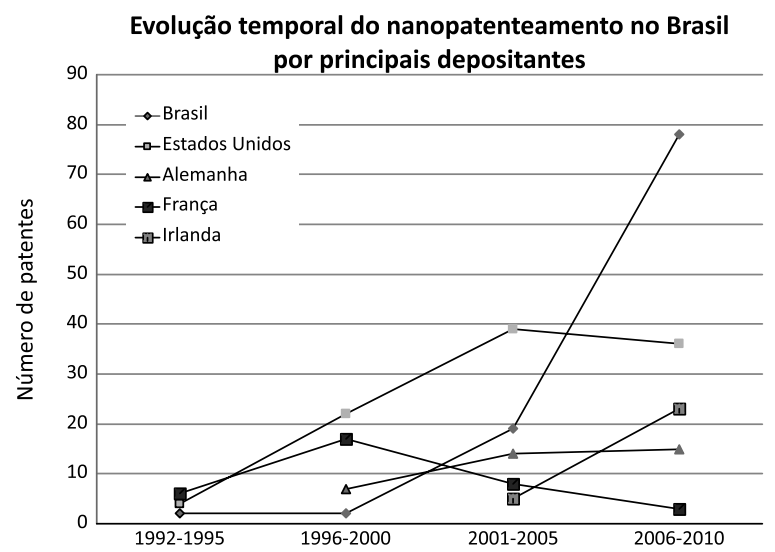

Figura 3. Evolução histórica por país de depósito das patentes em nanotecnologia e saúde no Brasil (1991-2010)

Os depósitos de patentes em nanotecnologia no Brasil foram classificados pela tipologia dos depositantes, ou seja, se pessoa física, jurídica e, nesse caso, mais especificamente, instituições de C\&T. Observa-se que as patentes depositadas por estrangeiros concentram-se em pessoas jurídicas, enquanto que as depositadas por residentes são de Instituições de C\&T. Um pequeno percentual de parcerias é verificado, sendo que a maioria envolve Instituições de Ciência e Tecnologia (ICTs). Nas 101 patentes de origem brasileira, foram identificados 80 diferentes depositantes, incluindo pessoas físicas e jurídicas, indicando uma grande dispersão de atores. As instituições depositantes de maior frequência são apresentadas na Tabela 4.

Tabela 4. Principais depositantes de origem brasileira em nanotecnologia e saúde (1991-2010)

\begin{tabular}{|c|c|}
\hline $\begin{array}{c}\mathrm{N}^{\circ} \text { de pedidos } \\
\text { de patente }\end{array}$ & Instituição depositante (estado) \\
\hline 17 & Universidade de São Paulo - USP (SP) \\
\hline 7 & Universidade Federal de Minas Gerais - UFMG (MG) \\
\hline 6 & Universidade Federal do Rio Grande do Sul - UFRGS (RS) \\
\hline
\end{tabular}

A Universidade de São Paulo (USP) depositou 17 patentes, sendo que destas, 9 são em parceria com outras instituições públicas. Das 17 patentes, 9 estão na CIP A61K (Preparações para finalidades médicas, odontológicas ou higiênicas) e um olhar mais detalhado no título e subgrupo principal na qual as patentes estão classificadas mostra que o foco são fármacos em nanocápsulas e nanopartículas.

Dos 7 depósitos da Universidade Federal de Minas Gerais (UFMG), apenas um é em parceria e com uma empresa privada. Esse depósito envolve equipamentos médicos (A61F) e outro documento traz inovação na área de implantes dentais (A61C). Os outros 5 depósitos da UFMG estão relacionados com a CIP A61K, relacionados a fármacos. A Universidade Federal do Rio Grande do Sul (UFRGS) possui 6 pedidos de patente. A UFRGS tem 5 na CIP A61K, envolvendo nanocápsulas/nanopartículas. A UFRGS tem ainda um depósito em parceria com a Universidade Federal do
Rio Grande (FURG) na CIP A61L, envolvendo nanofibras biodegradáveis. É importante notar que nenhum desses 30 documentos de patentes destes depositantes foi ainda concedida, estando em fases diferentes do processo de patenteamento, com publicação do pedido ou em arquivamento.

Nos 270 depósitos de patentes de origem estrangeira, foram identificados 191 diferentes depositantes, incluindo pessoas físicas e jurídicas. As instituições depositantes de maior frequência são: Elan Pharma International Ltd (Irlanda) com 26 patentes, L'Oreal (França) com 19 patentes, Abraxis Bioscience INC. (Estados Unidos) com 7 patentes, Advanced In Vitro Cell Technologies, S.L (Espanha) com 5 patentes e Novartis AG (Suíca) com 5 patentes.

A Elan Pharma International Ltd lidera o patenteamento em nanotecnologia e saúde dentre os não residentes no Brasil. Todos os seus depósitos estão na classificação A61K, como esperado, e observa-se pelo titulo que os depósitos são de composições e formulações de fármacos em escala nanométrica. A L'Oreal apresenta depósitos na área cosmética, destacando-se, no entanto, que há um considerável número de depósitos arquivados e extintos por falta de pagamento. Os 7 depósitos da Abraxis Bioscience estão na área de nanofármacos, destacando-se que seu foco está em antitumorais. A Advanced In Vitro Cell Technologies tem depositado patentes no Brasil envolvendo nanocápsulas e nanopartículas, em especial de quitosana. Novartis apresenta 5 depósitos em especial na área de nanopartículas, sendo 1 em pareceria com o Instituto de Tecnologia de Massachusetts.

Dentre esses 62 documentos analisados dos principais depositantes não residentes, 22 se encontram em fase de notificação nacional e 21 foram arquivados, 2 expedições de cartas patentes e 2 extinções da carta patente por falta de pagamento da anuidade. Também se observa em menor escala a participação de universidades públicas brasileiras; porém, sinalizando potencialidades para atuar nas demandas nacionais. ${ }^{38} \mathrm{Em}$ estudos posteriores serão analisadas as diferentes fases de notificação do processo de patenteamento vis-à-vis sociedades empresariais e foco da inovação.

\section{CONCLUSÃO}

O desenvolvimento em nanotecnologia continua a ser produzido em taxas exponenciais para uma gama de aplicações ampla e diversificada e, assim, a manipulação de partículas nanométricas tem aberto inúmeras oportunidades de desenvolvimento de novos produtos e materiais.

O desenrolar de patentes em nanotecnologias no Brasil é fato e este estudo demonstrou que os processos nanotecnológicos emergem significativamente no país, potencializando o desenvolvimento com a consequente disponibilização de produtos gerados

O impacto potencial da nanotecnologia na sociedade suscita debates sobre seus aspectos éticos, legais e sociais. Muitas das questões debatidas sobre as nanotecnologias não são novas nem exclusivas desta área de tecnologia, mas refletem as preocupações anteriores levantadas a respeito de outras tecnologias emergentes. No entanto, ao contrário de outras tecnologias emergentes do passado, a nanotecnologia tem o potencial de mudar profundamente não só o nosso padrão de vida e economia mundial, como o conceito de humanidade. Assim, sugerimos, adicionalmente, que outros estudos sejam também otimizidados, pois, da mesma forma que se desenvolvem as nanotecnologias, em paralelo, urge o desenvolvimento de metodologias de controle dos subprodutos advindos dos processos de produção, de forma a não se ter contaminações no ambiente e possíveis impactos na saúde, propiciando, também, que os gestores da sáude tenham condições de atuarem somente com os benefícios tecnológicos. 


\section{REFERÊNCIAS}

1. Duran, N.; Mattoso, L. H. C.; Morais, P. C.; Nanotecnologia: introdução, preparação e caracterização de nanomateriais e exemplos de aplicação, Artliber: São Paulo, 2006.

2. Rossi-Bergmann, B.; Ciência \& Cultura 2008, 60, 54.

3. Fernandes, M. F. M.; Filgueiras, C. A. L.; Quim. Nova 2008, 31, 2205.

4. Borschiver, S. G.; Maria José, O. C.; Santos, T. N.; Silva, F. C.; Brum, P. R. C.; Polímeros 2005, 15, 245.

5. Alves, O. L. Em Estudos estratégicos Nanotecnologia; Núcleo de Assuntos Estratégicos da Presidência da República: Brasília, 2004/2005, parte III; http://www.nae.gov.br/doc/estudos_estrategicos/estudo_ nanotecnologia.pdf, acessada em Setembro 2011.

6. MCT; Relatório Nanotecnologia: Investimentos, Resultados e Demandas, 2006; http://www.mct.gov.br/upd_blob/0008/8075.pdf, acessada em Dezembro 2010.

7. Lei $n^{\circ} 10.973$, de $02 / 12 / 2004$, que dispõe sobre incentivos à inovação e à pesquisa científica e tecnológica no ambiente produtivo, e dá outras providências; http://www.planalto.gov.br/ccivil_03/_ato2004-2006/2004/ lei/110.973.htm, acessada em Agosto 2011.

8. Zanetti-Ramos, B. G.; Creczynski-Pasa, T. B.; Rev. Bras. Cienc. Farm. 2008, 89, 95.

9. Alencar, M. S. M.; Tese de Doutorado, Universidade Federal do Rio de Janeiro, Brasil, 2008.

10. Silva, C. G.; Melo, L. C. P., coords.; Ciência, Tecnologia e Inovação: Desafio para a sociedade brasileira - Livro Verde, MCT/ABC: Brasília, 2001; http://www.mct.gov.br/index.php/content/view/18811.html, acessada em Outubro 2011.

11. Estratégia Nacional de Ciência, Tecnologia e Inovação 2012-2015, Balanço das Atividades Estruturantes 2011:2012; https://www. matrizlimpa.com.br/index.php/2012/03/inovacao-balanco-dasatividades/3979, acessada em Janeiro 2012.

12. Plano Plurianual 2012-2015; http://ppa20122015.planejamento.gov.br, acessada em Fevereiro 2012.

13. Instituto Nacional de Propriedade Intelectual - INPI; Alerta Tecnológico em Nanotecnologia: 2008; http://www.inpi.gov.br/index.php/quemsomos/noticias/ notas/403-alerta-tecnologico, acessada em Julho 2011.

14. Mirra, E.; J. Braz. Chem. Soc. 2006, 17, 7; http://www.scielo.br/pdf/jbcs/ v17n7/00.pdf, acessada em Maio 2011.

15. Schulte, J.; Nanotechnology: global strategies, industry trends and applications, John Wiley and Sons: Sussex, 2005.

16. Toma, H. E.; Quim. Nova 2005; 28 supl., S48.

17. Dagani, R.; Chem. Eng. News 2003, 28, 30; http://cen.acs.org/index. html, acessada em Maio 2012

18. Quina, F. H.; Quim. Nova 2004, 27, 1028.

19. Salamanca-Buentello, F.; Persad, D. L.; Court, E. B.; Martin, D. K.; Daar, A. S.; citar todos os autores; World PLoS Med (2005), 2, 5, e97. doi:10.1371/journal.pmed.0020097.

20. Premebida, A.; Tese de Doutorado, Universidade Federal do Rio Grande do Sul, Brasil, 2008.
21. The EFMN Annual Mapping Report 2004-2005; http://ec.europa.eu/ research/social-sciences/pdf/efmn-mapping-foresight_en.pdf, acessada em Agosto 2011.

22. Noronha, D. P.; Maricato, J. M.; Revista Eletrônica de Biblioteconomia e Ciência da Informação 2008, esp., 116.

23. Bibliometric Analysis of Research in Genomics During the 1990's; http://www.obs-ost.fr/fileadmin/medias/tx_ostdocuments/GenomiqueEngRevu.PDF, acessada em Setembro 2011.

24. Porter, A. L.; Cunningham, S. W.; Tech mining: exploiting new technologies for competitive advantage; John Wiley \& Sons: New Jersey, 2005.

25. Introduction STI Review No. 27, New Science and Technology Indicators for the Knowledge-Based Economy: Opportunities and Challenges, Organization for Economic Co-operation and Development: 2003; http://www.oecd.org/document/17/0,3746, en_2649_34273_2669841_1_1_1_1,00.html, acessada em Dezembro 2011.

26. Patents and Innovation: Trends and Policy Challenges, Organization for Economic Co-operation and Development: 2004; http://www.oecd.org/ dataoecd/48/12/24508541.pdf, acessada em Março 2012.

27. Maynard, A. D.; Aitken, R. J.; Butz, T.; Colvin, V.; Donaldson, K.; Oberdörster, G.; Philbert, M. A.; Ryan, J.; Seaton, A.; Stone, V.; Tinkle, S. S.; Tran, L.; Walker, N. J.; Warheit, D. D.; Nature 2006, 444, 267.

28. Colvin, V. L.; Nature Biotechnology 2003, 21, 1166.

29. Impacts of Manufactured Nanomaterials on Human Health and the Environment; US Environmental Protection Agency, http://es.epa.gov/ ncer/rfa/current/2003_nano.html, acessada em Abril 2012.

30. Antunes, A. M. S.; Alencar, M. S. M.; Silva, C. H.; Nunes, J.; Mendes, F. M. L.; Recent Patents in Nanotechnology 2012, 6, 29.

31. Milanez, D. H.; Dissertação de Mestrado, Universidade Federal de São Carlos, Brasil, 2011.

32. Alencar, M. S. M.; Porter, A. L.; Antunes, A. M. S.; Technological Forecasting \& Social Change 2007, 74, 1661.

33. Porter, A L.; Youtie, J.; Shapira, P.; Schoeneck, D. J.; J. Nanoparticle Res. 2008, 10, 715.

34. Pareto, V.; Quarterly Journal of Economics 1949, LXIII, 147.

35. Série Cadernos da Indústria ABDI XIX, ABDI: 2010; http://www.abdi. com.br/Estudo/Panorama\%20de\%20Nanotecnologia.pdf, acessada em Dezembro 2011.

36. Lei n 9.279, de 14/05/1996, que regula direitos e obrigações relativos a propriedade industrial, e dá outras providências; http://www.planalto. gov.br/ccivil_03/leis/L9279.htm, acessada em Agosto de 2011.

37. Lei $\mathrm{n}^{\circ} 10.196$, de 14/02/2001, de 14/05/ 1996, que regula direitos e obrigações relativos a propriedade industrial, e dá outras providências; http://www.planalto.gov.br/ccivil_03/leis/LEIS_2001/L10196.htm, acessada em Julho de 2011.

38. Martins, P. R.; Nanotecnologia, sociedade e meio ambiente, Xamã: São Paulo, 2006. 